\title{
Public Health Measures to Combat the Menace of Drug Abuse
}

\author{
Saurabh Rambiharilal Shrivastava*, Prateek Saurabh Shrivastava and Jegadeesh Ramasamy
}

Assistant Professor, Department of Community Medicine, Shri Sathya Sai Medical College \& Research Institute, Kancheepuram, India

\begin{abstract}
Drug abuse is defined as self-administration of a drug for non-medical reasons, in such amount and periodicity which may impair the ability to function adequately and which may result in social, physical, or emotional harm. A wide range of biological, genetic, medical, social, and environmental factors have influenced people from the community for the drug abuse. Drug abuse tends to affect the individuals from the middle-aged and later years of life substantially, the aftermaths of use not only results in adverse health consequences, but even affects the quality of life, family interdynamics, and burdening of the health system. Owing to the adverse impact on all age-groups of the society, it is of prime importance to design and formulate an effective community based and a holistic strategy to address the needs of the drug abuser and their family comprehensively. Multiple measures have been proposed to assist families, health professionals, schools and other community workers with identifying at risk youth and aid in reducing or eliminating risk factors through prevention and treatment programs. To conclude, although, the problem of drug abuse is complex and of significant magnitude, implementation of targeted interventions in different settings, well-supported by the dedicated team of health workers can definitely reduce the problem of the disease comprehensively.
\end{abstract}

Keywords: Drugs; Drug abuse; Pharmacist; Health; World Health Organization

\section{Introduction}

\section{Drug abuse}

Drug abuse is defined as self-administration of a drug for nonmedical reasons, in such amount and periodicity which may impair the ability to function adequately and may result in social, physical, or emotional harm [1]. Drug or substance abuse has been recognized as a major public health problem across the globe [2]. Owing to the multiple aspects of the drug abuse such as the magnitude, the range of consequences, the types of substances consumed, the psychosocial correlates, and the impact on the health care delivery system, it is a problem of great public health significance [3,4]. Furthermore, the problem of drug abuse has been typically associated with adolescents and individuals in the economic productive age-group, that indirectly casts a significant impact on the quality of life of the individual and on the economic growth of the country $[2,4,5]$.

\section{Magnitude of the problem}

The World Health Organization has estimated that more than 225 million individuals or one in every twenty adults have consumed an illegal drug once in the year 2010 [4]. The public health concern of drug abuse does not recognize any boundaries and affects all the persons irrespective of their socioeconomic status or their belonging from a developed or developing country $[1,3,4]$. In addition, globally more than fifteen million persons are indulged in drug abuse and the problem of injectable drug abuse has been reported in more than 145 nations [6,7]. In fact, it was reported that in the year 2011, almost 22 million people have consumed an illicit drug within a span of one month in the United States alone [8]. Furthermore, the problem of drug abuse not only runs in families, but is significantly influenced by the environmental factors - influencing attitudes toward drug use and serving as a source of drugs of abuse $[9,10]$.

\section{The multidimensional determinants}

A wide range of biological, genetic, medical, social, and environmental factors have influenced people for the drug abuse $[11,12]$. These multidimensional factors include parameters such as genetic predisposition [11,13]; childhood behavioral problems [14]; adverse childhood events like physical / emotional / sexual abuse or neglect [15]; problem family or broken family $[1,16]$; family conflicts and quality of parenting - strict parents [16,17]; presence of drug abuse in parents $[1,14,16,17]$; peer pressure / adolescents' curiosity / pleasure seeking / low levels of self-confidence or self-control $[14,16]$; socioeconomic status $[6,14,17]$; history of academic failures $[6,17]$; history of antisocial and aggressive behavior $[1,9,10]$; pre-existing psychological disorder in individual or family members $[16,18]$; increase in prescriptions for neuropsychiatric medications like opioids / stimulants / sedatives [19,20]; weak legislative measures [6,14]; rise in the sale of non-prescription or over-the-counter drugs [21]; and no effective strategies to curb new drugs usage that are sold through internet [22]. In fact, a theory of planned behavior has been proposed to determine factors that can influence a person for drug abuse or smoking [23].

The public health consequences of the drug abuse on the individual and the society

As already discussed, drug abuse tends to affect the individuals from the middle-age group substantially, the aftermaths of drug abuse not only results in adverse health consequences, but even affects the quality of life and family inter-dynamics $[24,25]$. Substance abuse has produced a significant impact on health and social dimensions like poor academic performance [26]; increase in the incidence of school dropouts [6]; rise in cases of juvenile delinquency [27]; aggravated cases of familial disharmony [26]; enhanced cardiovascular risks [28]; psychological morbidities like depression and adjustment disorders

*Corresponding author: Saurabh Rambiharilal Shrivastava, Department of Community Medicine, Shri Sathya Sai Medical College \& Research Institute, Ammapettai village, Thiruporur - Guduvancherry Main Road, SembakkamPost Kancheepuram-603108, Tamil Nadu, India, Tel: +919884227224; E-mail: drshrishri2008@gmail.com

Received March 06, 2014; Accepted March 16, 2014; Published April 09, 2014

Citation: Shrivastava SR, Shrivastava PS, Ramasamy J (2014) Public Health Measures to Combat the Menace of Drug Abuse. Primary Health Care 4: e110. doi:10.4172/2167-1079.1000e110

Copyright: @ 2014 Shrivastava SR, et al. This is an open-access article distributed under the terms of the Creative Commons Attribution License, which permits unrestricted use, distribution, and reproduction in any medium, provided the original author and source are credited. 
$[13,29]$; more frequent adoption of high risk behavior [26,30]; HIV / AIDS infection [13,26]; cerebro-vascular accidents [31]; metabolic complications in elderly [32]; drug-abuse related deviant or criminal activities [26]; favors trauma recurrence and reduces the trauma-free period [29,33,34]; casualties due to interpersonal violence [26]; and rate of admission in hospitals owing to drug overdose or infections from needles $[24,35]$. In addition, drug abuse imposes a substantial economic burden on the country because of the added direct and indirect medical and non-medical expenditures [25].

\section{Drug abuse: Identified challenges or perceived barriers}

Although, multiple strategies have been implemented in different countries to counter the menace of drug abuse, but the outcomes have not been encouraging enough. Evaluation studies have revealed multiple bottlenecks in the current strategies such as poor political will; lack of target oriented measures; socio-cultural barriers; low level of community awareness about the adverse consequences of drug abuse; inadequate strategies; loopholes in the current legislative measures; no counseling on substance abuse by the outreach workers; lack of tested screening tools; lack of follow-up services; and resource limitations, in the exacerbation of the problem [1,6,25,36-38].

\section{Proposed measures}

Owing to the adverse impact on all age-groups of the society, it is of prime importance to design and formulate an effective community based and a holistic strategy to address the needs of the drug abuser and their family comprehensively. Multiple measures such as identifying the socio-cultural and psychological determinants that may determine the use of illicit drugs [24,39]; creating awareness about drug abuse and their adverse consequences through aid of appropriate mass media tools [6,38]; delivering customized information suitable to the target audience in a culturally sensitive manner [40]; developing family prevention programs in the form of multi-dimensional family therapy and individual cognitive behavioral therapy [41,42]; enabling community to address the issues of substance abuse through training programs [43]; promoting free education and implementing innovative strategies to minimize the rates of school drop-outs [40,44]; inculcating self-confidence in school students [16]; employing nurses in schools to safeguard the students [45]; facilitating community and school prevention campaigns [17]; advocating timely and complete management of drug abuse victims [46]; sensitizing clinicians to identify patients at risk for nonprescription drug abuse [21]; strengthening preclinical assessment to predict substance abuse liability [47]; encouraging exercises as a potential treatment for drug abuse [48]; developing a standardized strategy to monitor response to treatment [48]; building mechanisms for tracking and monitoring prescription drug abuse [38]; improving data collection on drug overdose fatalities $[6,38]$; capacity building for the tools and methods desired for toxicological screening [49]; involving all stakeholders including the pharmacists to work together as a team [7,50]; fostering linkages between local, national and international agencies in the field of development, organization, monitoring and evaluation of treatment and other services [7]; formulating strategies in collaboration with international agencies to monitor the sale of over-the-counter drugs and through internet [22]; and enforcing stricter penalties for individuals who are involved in trade of illicit drugs [1,6]; have been proposed to assist families, health professionals, schools and other community workers with identifying at risk youth and aid in reducing or eliminating risk factors through prevention and treatment programs.

\section{References}

1. Park K (2009) Medicine and social sciences. In: Park K, eds. Textbook of Preventive and Social Medicine. 20th edn. Jabalpur: Banarsidas Bhanot, 608609.

2. Degenhardt L, Chiu WT, Sampson N, Kessler RC, Anthony JC, et al. (2008) Toward a global view of alcohol, tobacco, cannabis, and cocaine use: findings from the WHO World Mental Health Surveys. PLoS Med 5: e141.

3. Babor TF, Caetano R (2006) Subtypes of substance dependence and abuse: implications for diagnostic classification and empirical research. Addiction 101 Suppl 1: 104-110.

4. UNODC (2013) World drug report 2012

5. Kertesz SG, Khodneva Y, Richman J, Tucker JA, Safford MM, et al. (2012) Trajectories of drug use and mortality outcomes among adults followed over 18 years. J Gen Intern Med 27: 808-816.

6. World Health Organization (2011) Global status report on alcohol and health 2011.

7. World Health Organization (2014) Management of substance abuse - Facts and figures

8. Substance abuse and mental health services administration (2012) Results from the 2011 national survey on drug use and health: Summary of national findings.

9. Merikangas KR, Stolar M, Stevens DE, Goulet J, Preisig MA, et al. (1998) Familial transmission of substance use disorders. Arch Gen Psychiatry 55: 973-979.

10. Kendler KS, Ohlsson H, Sundquist K, Sundquist J (2013) Within-family environmental transmission of drug abuse: a Swedish national study. JAMA Psychiatry 70: 235-242.

11. Nielsen DA, Utrankar A, Reyes JA, Simons DD, Kosten TR (2012) Epigenetics of drug abuse: predisposition or response. Pharmacogenomics 13: 1149-1160.

12. Kreek MJ, Nielsen DA, Butelman ER, LaForge KS (2005) Genetic influences on impulsivity, risk taking, stress responsivity and vulnerability to drug abuse and addiction. Nat Neurosci 8: 1450-1457.

13. Schulden JD, Lopez MF, Compton WM (2012) Clinical implications of drug abuse epidemiology. Psychiatr Clin North Am 35: 411-423.

14. Hawkins JD, Catalano RF, Arthur MW (2002) Promoting science-based prevention in communities. Addict Behav 27: 951-976.

15. Dube SR, Felitti VJ, Dong M, Chapman DP, Giles WH, et al. (2003) Childhood abuse, neglect, and household dysfunction and the risk of illicit drug use: the adverse childhood experiences study. Pediatrics 111: 564-572.

16. Geramian N, Akhavan S, Gharaat L, Tehrani AM, Farajzadegan Z (2012) Determinants of drug abuse in high school students and their related knowledge and attitude. J Pak Med Assoc 62: S62-66.

17. National Institute on Drug Abuse (2010) A research-based guide for parents educators and community leaders. 2nd ed. Bethesda, Maryland, USA

18. Santucci K (2012) Psychiatric disease and drug abuse. Curr Opin Pediatr 24 233-237.

19. Moloney ME, Konrad TR, Zimmer CR (2011) The medicalization of sleeplessness: a public health concern. Am J Public Health 101: 1429-1433.

20. Manchikanti L, Helm S 2nd, Fellows B, Janata JW, Pampati V, et al. (2012) Opioid epidemic in the United States. Pain Physician 15: ES9-38.

21. Conca AJ, Worthen DR (2012) Nonprescription drug abuse. J Pharm Pract 25: 13-21.

22. Davis GG (2012) Drug abuse: newly-emerging drugs and trends. Clin Lab Med 32: $407-414$

23. Giordano GN, Ohlsson H2, Kendler KS3, Winkleby MA4, Sundquist K5, et al. (2014) Age, period and cohort trends in drug abuse hospitalizations within the total Swedish population (1975-2010). Drug Alcohol Depend 134: 355-361.

24. Bashirian S, Hidarnia A, Allahverdipour H, Hajizadeh E (2012) Application of the theory of planned behavior to predict drug abuse related behaviors among adolescents. J Res Health Sci 12: 54-60.

25. Wickizer TM (2013) State-level estimates of the economic costs of alcohol and 
Citation: Shrivastava SR, Shrivastava PS, Ramasamy J (2014) Public Health Measures to Combat the Menace of Drug Abuse. Primary Health Care 4: e110. doi:10.4172/2167-1079.1000e110

drug abuse. J Health Care Finance 39: 71-84.

26. Aarons GA, Brown SA, Coe MT, Myers MG, Garland AF, et al. (1999) Adolescent alcohol and drug abuse and health. J Adolesc Health 24: 412-421.

27. Contreras Martínez L1, Molina Banqueri V, Cano Lozano MC (2012) [Drug abuse in adolescent offenders: analysis of the psychosocial variables involved]. Adicciones 24: 31-38.

28. Angell PJ, Chester N, Sculthorpe N, Whyte G, George K, et al. (2012) Performance enhancing drug abuse and cardiovascular risk in athletes: implications for the clinician. Br J Sports Med 46 Suppl 1: i78-84.

29. Pandiyan K, Chandrasekhar H, Madhusudhan S (2012) Psychological morbidity among female commercial sex workers with alcohol and drug abuse. Indian $J$ Psychiatry 54: 349-351.

30. Cordovilla Guardia S, Rodríguez-Bolaños S, Guerrero López F, Lara-Rosales R, Pino Sánchez F, et al. (2013) Alcohol and/or drug abuse favors trauma recurrence and reduces the trauma-free period. Med Intensiva 37: 6-11.

31. Fonseca AC, Ferro JM (2013) Drug abuse and stroke. Curr Neurol Neurosci Rep 13: 325

32. Nubukpo P, Clément JP (2013) [Medical drug abuse and aging]. Geriatr Psychol Neuropsychiatr Vieil 11: 305-315.

33. Caufeild J, Singhal A, Moulton R, Brenneman F, Redelmeier D, et al. (2004) Trauma recidivism in a large urban canadian population. J Trauma 57: 872876.

34. Farley M, Golding JM, Young G, Mulligan M, Minkoff JR (2004) Trauma history and relapse probability among patients seeking substance abuse treatment. J Subst Abuse Treat 27: 161-167.

35. Barlas S (2013) Prescription drug abuse hits hospitals hard: tighter federal steps aim to deflate crisis. P T 38: 531-534.

36. Samouei R, Sohrabi A, Yarmohammadian MH (2013) Why some previous drug abuse preventive programs had low effectiveness? Med Arh 67: 68-72.

37. Hallfors D, Van Dorn RA (2002) Strengthening the role of two key institutions in the prevention of adolescent substance abuse. J Adolesc Health 30: 17-28.
38. Phillips J (2013) Prescription drug abuse: problem, policies, and implications Nurs Outlook 61: 78-84.

39. Chakravarthy B, Shah S, Lotfipour S (2013) Adolescent drug abuse - awareness \& prevention. Indian J Med Res 137: 1021-1023.

40. Botvin GJ, Griffin KW (2007) School-based programmes to prevent alcohol, tobacco and other drug use. Int Rev Psychiatry 19: 607-615.

41. Liddle HA (1999) Theory development in a family-based therapy for adolescent drug abuse. J Clin Child Psychol 28: 521-532.

42. Rowe CL (2012) Family therapy for drug abuse: review and updates 20032010. J Marital Fam Ther 38: 59-81.

43. Pringle JL, Kowalchuk A, Meyers JA, Seale JP (2012) Equipping Residents to Address Alcohol and Drug Abuse: The National SBIRT Residency Training Project. J Grad Med Educ 4: 58-63.

44. Gauffin K, Vinnerljung B, Fridell M, Hesse M, Hjern A (2013) Childhood socioeconomic status, school failure and drug abuse: a Swedish national cohort study. Addiction 108: 1441-1449.

45. Embrey ML (2012) Smart Moves, Smart Choices: how school nurses can help safeguard students from teen prescription drug abuse. NASN Sch Nurse 27 : 101-102.

46. Chen IC, Hung DZ, Hsu CH, Wu ML, Deng JF, et al. (2012) Drug abuse-related accidents leading to emergency department visits at two medical centers. J Chin Med Assoc 75: 234-239.

47. Marusich JA, Lefever TW, Novak SP, Blough BE, Wiley JL (2013) Prediction and Prevention of Prescription Drug Abuse: Role of Preclinical Assessment of Substance Abuse Liability. Methods Rep RTI Press.

48. Lennox RD, Sternquist MA, Paredes A (2013) A simplified method for routine outcome monitoring after drug abuse treatment. Subst Abuse 7: 155-169.

49. Rosso GL (2013) [Analysis of tools, methods and results of toxicological screening for detection of drug abuse in Italian professional drivers]. Med Lav 104: $30-43$.

50. Lynas K (2013) Pharmacists can play a key role in implementing new national strategy to combat prescription drug abuse. Can Pharm J (Ott) 146: 128-129. 